CLINICAL ALERT

\title{
Haemophagocytic lymphohistiocytosis: A fulminant syndrome associated with multiorgan failure and high mortality that frequently masquerades as sepsis and shock
}

\author{
B Price, J Lines, D Lewis, N Holland \\ Brendon Price, Jennifer Lines and Nicole Holland are based in the Department of Haematology, and Dorothy Lewis in the Department of \\ Histopathology, at Lancet Laboratories, Johannesburg, South Africa
}

Corresponding author: B Price (pricebrendon@yahoo.com)

\begin{abstract}
Acquired haemophagocytic lymphohistiocytosis (HLH) is a condition involving cytokine overproduction by defective cytotoxic T lymphocytes and natural killer cells, resulting in life-threatening cytopaenias and multiorgan infiltration and dysfunction. Triggers for acquired HLH vary and include viruses, malignancies and autoimmune conditions. Recent reports suggest that HLH may be underdiagnosed owing to variable clinical presentations, diagnostic criteria and a low level of awareness on the part of medical personnel, thus delaying prompt treatment and contributing to high mortality rates. Five patients in whom acquired HLH was diagnosed, following bone marrow investigations, during the period of May - September 2013 are presented. All were at an advanced stage of their disease at time of diagnosis. The three patients who were HIV-positive had a coexisting malignancy at the time of HLH diagnosis, which may have triggered HLH. A definite trigger was not identified in the remaining two HIV-negative patients despite early concerns regarding autoimmune disease. Two patients received timeous diagnosis, started chemotherapy and are currently improving. The remaining three succumbed to their illness. Aquired HLH in adults may be more common in the acute care setting than currently appreciated. As awareness of this condition and its treatment is currently low, it may remain undiagnosed until the disease has evolved into multiorgan failure. Fever in the absence of infectious agents, marked hyperferritinaemia, unexplained cytopenias, organomegaly or liver dysfunction should raise the suspicion of HLH. Timeous introduction of therapy will improve outcomes.
\end{abstract}

S Afr Med J 2014;104(6):401-406. DOI:7196/SAMJ.7810

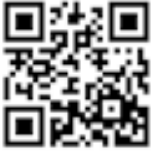

Haemophagocytic lymphohistiocytosis (HLH) is a condition in which there is pathological, unregulated cytokine-mediated stimulation of the immune system by functionally defective cytotoxic $\mathrm{T}$ lymphocytes (CTLs) and natural killer (NK) cells. ${ }^{[1-4]}$ Massive amounts of proinflammatory cytokines (interleukins 1, 6 and 10, granulocyte macrophage colony stimulating factor, tumour necrosis factor- $\alpha$ and interferon- $\gamma$ (IFN- $\gamma$ )) released by CTLs result in increased production of non-neoplastic lymphocytes and macrophages/histiocytes, along with unremitting fever. Thereafter, haemophagocytosis and infiltration of organs by cytokine-activated histiocytes result in organomegaly, multiorgan dysfunction, life-threatening cytopenias and sepsis. ${ }^{[1]}$

HLH may be classified as primary/genetic or secondary/acquired (Table 1). In genetic HLH, a mutation occurs in one of the proteins responsible for intracellular vesicle docking and release of preformed proapoptotic granzyme and perforin. ${ }^{[1-4]}$ This in turn reduces the ability of CTLs and NK cells to induce apoptosis of antigenpresenting cells and clonally expanded $\mathrm{T}$ lymphocytes. In acquired HLH, the exact cause of depressed CTL and NK cell activity is less well understood, but it is strongly associated with specific viral infections, malignancies and autoimmune disorders. ${ }^{[3,5]}$ It is postulated that patients who develop acquired HLH may in fact have an underlying (as yet unidentified) genetic predisposition. ${ }^{[6]}$

Genetic HLH arises in childhood, usually before 1 year of age, but there are reports of adults presenting with primary HLH at advanced ages. $^{[1,7]}$ As it is due to a genetic mutation, the only chance of cure is stem cell transplantation.

Acquired HLH can occur at any age and is treated with combination chemotherapy via the HLH-94 trial protocol ${ }^{\left[{ }^{[8]}\right.}$ along with treatment for the suspected trigger (e.g. infection). In cases with a clear trigger for acquired HLH (e.g. cytomegalovirus (CMV), HIV), reports of complete cure (using immunoglobulins or antiretrovirals) without the need for additional chemotherapy have been described. ${ }^{[9-1]}$ Patients who are diagnosed with acquired HLH that does not respond to the HLH-94 chemotherapy regimen or relapse post-chemotherapy are referred for stem cell transplantation. ${ }^{[8]}$

Much of our knowledge about HLH is derived from Swedish paediatric studies in the context of primary $\mathrm{HLH}$, where an incidence of 0.12/100 000/year has been estimated. ${ }^{[6]}$ The exact incidence of acquired HLH in adults is unknown, although a single-institution retrospective analysis of malignancy-associated acquired HLH puts the estimate at $0.36 / 100000 /$ year. $^{[12]}$

The diagnostic criteria for HLH are published by the Histiocyte Society (http://www.histiocytesociety.org) and require either a confirmed molecular diagnosis of genetic mutations known to be associated with HLH or the presence of at least 5/8 clinical and laboratory criteria. These include:

- prolonged fever

- splenomegaly

- haemophagocytosis (in bone marrow, lymph node or spleen)

- cytopenias 
Table 1. Types of $\mathrm{HLH}^{\star}$

\begin{tabular}{|c|c|c|}
\hline Type & Subtype & Underlying cause/trigger \\
\hline \multirow[t]{2}{*}{ Genetic/primary } & Familial & $\begin{array}{l}\text { Autosomal and X-linked recessive genetic mutations of proteins } \\
\text { involved in granzyme/perforin-mediated cytolytic function in CTL/NK } \\
\text { cells: PRF1, UNC13D, STXBP2, RAB27A, STX11, SH2D1A, XIAP }\end{array}$ \\
\hline & Immune deficiency-associated & $\begin{array}{l}\text { Chédiak-Higashi syndrome } \\
\text { Griscelli syndrome } \\
\text { X-linked lymphoproliferative syndrome }\end{array}$ \\
\hline \multirow[t]{3}{*}{ Acquired/secondary } & Infection-associated & $\begin{array}{l}\text { Viral (EBV, HSV, HIV, CMV, B19V) } \\
\text { Bacterial, protozoal, mycobacterial }\end{array}$ \\
\hline & Malignancy-associated & $\begin{array}{l}\text { Lymphoma } \\
\text { Leukaemia (particularly T- and NK-cell types) } \\
\text { Solid tumours (rare) }\end{array}$ \\
\hline & $\begin{array}{l}\text { Rheumatic disease-associated } \\
\text { (macrophage activation syndrome) }\end{array}$ & $\begin{array}{l}\text { SLE, scleroderma, Sjögren's syndrome, mixed connective tissue } \\
\text { disorders }\end{array}$ \\
\hline \multicolumn{3}{|c|}{ 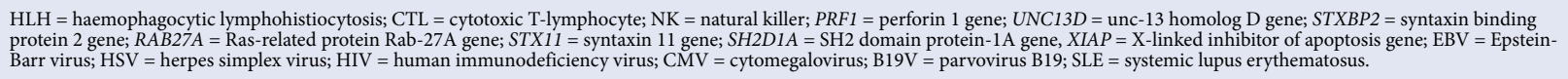 } \\
\hline \multicolumn{3}{|c|}{${ }^{*}$ Adapted from Lehmberg and Ehl. ${ }^{[1]}$ Usmani et al. ${ }^{[2]}$ Janka and zur Stadt ${ }^{[3]}$ and Arceci. ${ }^{\left[{ }^{[6]}\right.}$} \\
\hline
\end{tabular}

- fasting hypertriglyceridaemia or hypofibrinogenaemia

- hyperferritinaemia

- low/absent NK cell activity

- elevated soluble CD25 (interleukin-2 receptor) levels.

HLH can mimic many other conditions in its early stages (Table 2). It may therefore be underdiagnosed in patients with infection or malignancy who present with systemic inflammatory response syndrome (SIRS) and acute multiorgan dysfunction. ${ }^{[13,14]} \mathrm{A}$ high index of suspicion is required to promptly initiate therapy in these patients.

Because awareness of acquired HLH is limited, it typically has a high mortality rate $(50-100 \%)$, partly as a reslt of delayed diagnosis and treatment. ${ }^{[14]}$ Recent studies suggest that acquired HLH is an under-recognised cause of death in adult intensive care units (ICUs) ${ }^{[13,15]}$ Patients usually present with features of SIRS (including pyrexia of unknown origin, tachycardia and leucopenia) and disseminated intravascular coagulation (DIC), organomegaly (specifically splenomegaly with or without hepatomegaly), and may additionally exhibit hepatic dysfunction, neurological deficits or septic features ${ }^{[1-3,6,13,1,5]}$ As not all diagnostic features may be present initially, it is essential to monitor patients clinically and biochemically at regular intervals. In the early stages, there may be mild manifestations (e.g. skin rashes) that resolve spontaneously with subsequent exacerbations. ${ }^{[1]}$

Importantly, haemophagocytosis is not specific to HLH and can be demonstrated in various non-HLH conditions such as post-blood transfusion, haemolysis, myelodysplasia/bone marrow failure or sepsis. ${ }^{[4,5,13,15]}$ Moreover, haemophagocytosis may not be seen in up to $20 \%$ of initial bone marrow biopsies ${ }^{[16]}$ and therefore, despite the nomenclature, can neither be diagnosed nor excluded solely on the basis of presence or absence of haemophagocytosis. ${ }^{[1,15]}$

We describe five cases of acquired HLH that were diagnosed over the course of 5 months (May - September 2013 ) in private hospitals in the greater Johannesburg area, South Africa (SA), with the aim of raising awareness and increasing the diagnostic pickup rate of acquired HLH in adult patients admitted to wards and ICUs with multiorgan dysfunction and/or presumed sepsis/SIRS. Although only three patients in this series were HIV-positive, the high burden of HIV in SA may make this condition more common, potentially triggered by coexisting HIV-associated infections and malignancies.

All patients were diagnosed with acquired HLH following bone marrow aspiration and trephine (BMAT). Clinical information (viz. presenting signs and symptoms, temperature trends, organomegaly) was obtained either from the bedside at time of BMAT or alternatively via communication with the treating physician. All laboratory data were accessed on the password-protected Meditech software system at Lancet Laboratories.

The clinical and laboratory details of the cases are shown in Table 3. Four cases fulfilled the diagnostic criteria for HLH. These include at least 5/8 criteria (listed as B1 - B8). No genetic mutational analyses were performed (A). Individual results that fit the HLH diagnostic criteria are highlighted in bold. Case 2 fulfilled only four criteria, but was included in the case series in view of her markedly raised ferritin level $(24370 \mu \mathrm{g} / \mathrm{l})$, hepatomegaly and active haemophagocytosis. (Had NK cell activity and/or CD25 assays been available, these may have been able to confirm the diagnosis conclusively.)

All patients were young adults. Cases 2 and 4 tested positive for HIV prior to admission and were receiving treatment. During admission, a drug-resistance polymerase chain reaction (PCR) screen performed on case 2 showed resistance to efavirenz. Case 1, who was initially HIV-negative according to an enzyme-linked immunosorbent assay (ELISA) and p24 antigen assay, seroconverted during the course of treatment.

Cases 1 and 2 were diagnosed with diffuse large B-cell lymphoma at the time of HLH diagnosis. Neither had undergone chemotherapy for lymphoma prior to HLH diagnosis. Case 2 additionally had a prior history of high-grade ductal carcinoma. Case 4 had been treated for Kaposi's sarcoma (KS) prior to HLH diagnosis.

All patients had prolonged fever prior to the diagnosis of HLH. This feature is consistent among HLH patients and is due to CTL/ NK-mediated hypercytokinaemia rather than to specific infectious agents. ${ }^{[1,4]}$ Fevers generally do not resolve despite the use of empiric antibiotics.

Splenomegaly was assessed either clinically or radiologically, absence of splenomegaly in cases 2 and 4 being confirmed on radiological imaging. Splenomegaly is a fairly consistent feature in HLH and is due to organ infiltration by activated histiocytes and 
Table 2. Mechanisms involved and differential diagnoses of typical clinical and laboratory findings in $H_{L} H^{\star}$

\begin{tabular}{|c|c|c|}
\hline Pathology & Mechanism & Differential diagnosis \\
\hline Cytopenia/s & Haemophagocytosis via activated histiocytes & $\begin{array}{l}\text { Bone marrow hypoplasia/ failure } \\
\text { Bone marrow infiltration (malignant, infective) } \\
\text { Drug-induced myelotoxicity (e.g. HAART, } \\
\text { chemotherapy) } \\
\text { Sepsis } \\
\text { ITP/TTP } \\
\text { Sequestration (e.g. splenomegaly) }\end{array}$ \\
\hline Liver dysfunction & $\begin{array}{l}\text { Infiltration by activated histiocytes } \\
\text { Hepatocyte damage }\end{array}$ & $\begin{array}{l}\text { Viral hepatitis } \\
\text { Drug-induced hepatitis } \\
\text { Warfarin toxicity } \\
\text { DIC } \\
\text { Sepsis }\end{array}$ \\
\hline Fever & Pro-inflammatory cytokine release by CTL/NK cells & Infection \\
\hline Neurological deficit/s & Demyelination & $\begin{array}{l}\text { Infections (meningitis, encephalitis) } \\
\text { CVA, space-occupying lesion }\end{array}$ \\
\hline Hyperferritinaemia & $\begin{array}{l}\text { Released from activated histiocytes } \\
\text { ? Released from damaged hepatocytes } \\
\text { Ferritin receptor down-regulation }\end{array}$ & $\begin{array}{l}\text { Sepsis } \\
\text { Anaemia of chronic disorders } \\
\text { Iron overload disorders } \\
\text { SLE } \\
\text { Fulminant hepatic failure }\end{array}$ \\
\hline Hypertriglyceridaemia & $\begin{array}{l}\text { Liver infiltration by histiocytes } \\
\text { Decreased levels of lipoprotein lipase }\end{array}$ & $\begin{array}{l}\text { Dyslipidaemia } \\
\text { Diabetes } \\
\text { Nephrotic syndrome } \\
\text { Drugs }\end{array}$ \\
\hline Hypofibrinogenaemia & Liver infiltration & $\begin{array}{l}\text { DIC } \\
\text { Liver failure }\end{array}$ \\
\hline Hepatomegaly/splenomegaly & Organ infiltration by activated histiocytes & $\begin{array}{l}\text { EPTB } \\
\text { Malignancies (e.g. CML, hepatic metastases) } \\
\text { Infections (e.g. malaria) } \\
\text { Haemolytic states } \\
\text { Extramedullary haematopoiesis } \\
\text { Storage disorders }\end{array}$ \\
\hline $\begin{array}{l}\text { Cutaneous manifestations } \\
\text { (commonly panniculitis and/ } \\
\text { or purpura) }\end{array}$ & Histiocytic and lymphocytic infiltration & $\begin{array}{l}\text { Eczema } \\
\text { Erythema nodosum } \\
\text { Panniculitis } \\
\text { Drug-related } \\
\text { Kawasaki disease }\end{array}$ \\
\hline \multicolumn{3}{|c|}{$\begin{array}{l}\text { HLH = haemophagocytic lymphohistiocytosis; HAART }=\text { highly active antiretroviral therapy; ITP }=\text { idiopathic thrombocytopenic purpura; } \text { TTP }=\text { thrombotic thrombocytopenic purpura; } \\
\text { DIC = disseminated intravascular coagulation; CTL = cytotoxic T-lymphocyte; NK = natural killer; CVA = cerebrovascular accident; SLE = systemic lupus erythematosus; } \\
\text { EPTB = extrapulmonary tuberculosis; CML = chronic myeloid leukaemia. }\end{array}$} \\
\hline
\end{tabular}

lymphocytes. ${ }^{[1,2]}$ Hepatomegaly may similarly develop and commonly results in deranged liver enzymes secondary to hepatocyte damage. Organomegaly was been shown to be present in $90 \%$ of HLH patients in a recent Indian case series. ${ }^{[14]}$

All patients exhibited cytopenias during their stay, although cell counts often fluctuated markedly, most commonly following transfusion of blood products. As a result, the diagnostic bi-/pancytopenia may not be present following blood/platelet transfusion, a fact to be borne in mind when working up a patient for suspected HLH. Importantly, underlying neutropenia may be masked if recombinant growth factors (e.g. filgrastim ) have recently been administered.

All the patients demonstrated haemophagocytosis in the bone marrow, probably because all were at an advanced stage of illness at the time of BMAT and their haemophagocytosis was well established. The presence of haemophagocytosis signalled the possibility of HLH and prompted urgent communication with the treating physicians and additional focused laboratory investigations including ferritin, fibrinogen and triglyceride levels.

Three patients had raised triglycerides above the diagnostic $3 \mathrm{mM}$ level, although the remaining two showed levels closely approaching this $(2.91 \mathrm{mM}$ and $2.95 \mathrm{mM})$. Fasting hypertriglyceridaemia is seen in $\sim 70 \%$ of HLH patients and is thought to be the result of cytokine-mediated lipoprotein lipase inhibition. ${ }^{[1,13]}$ Caution should be applied when interpreting this parameter in patients known to be dyslipidaemic, when a fibrinogen level should preferentially be tested as it is scored under the same diagnostic criterion.

Ferritin and fibrinogen are liver-derived positive acute-phase reactants. In the normal inflammatory response, levels of both should increase. However, markedly raised ferritin levels in HLH denote excessive production by activated histiocytes and possibly release 
Table 3. Case series of patients diagnosed with acquired $\mathrm{HLH}^{\star}$

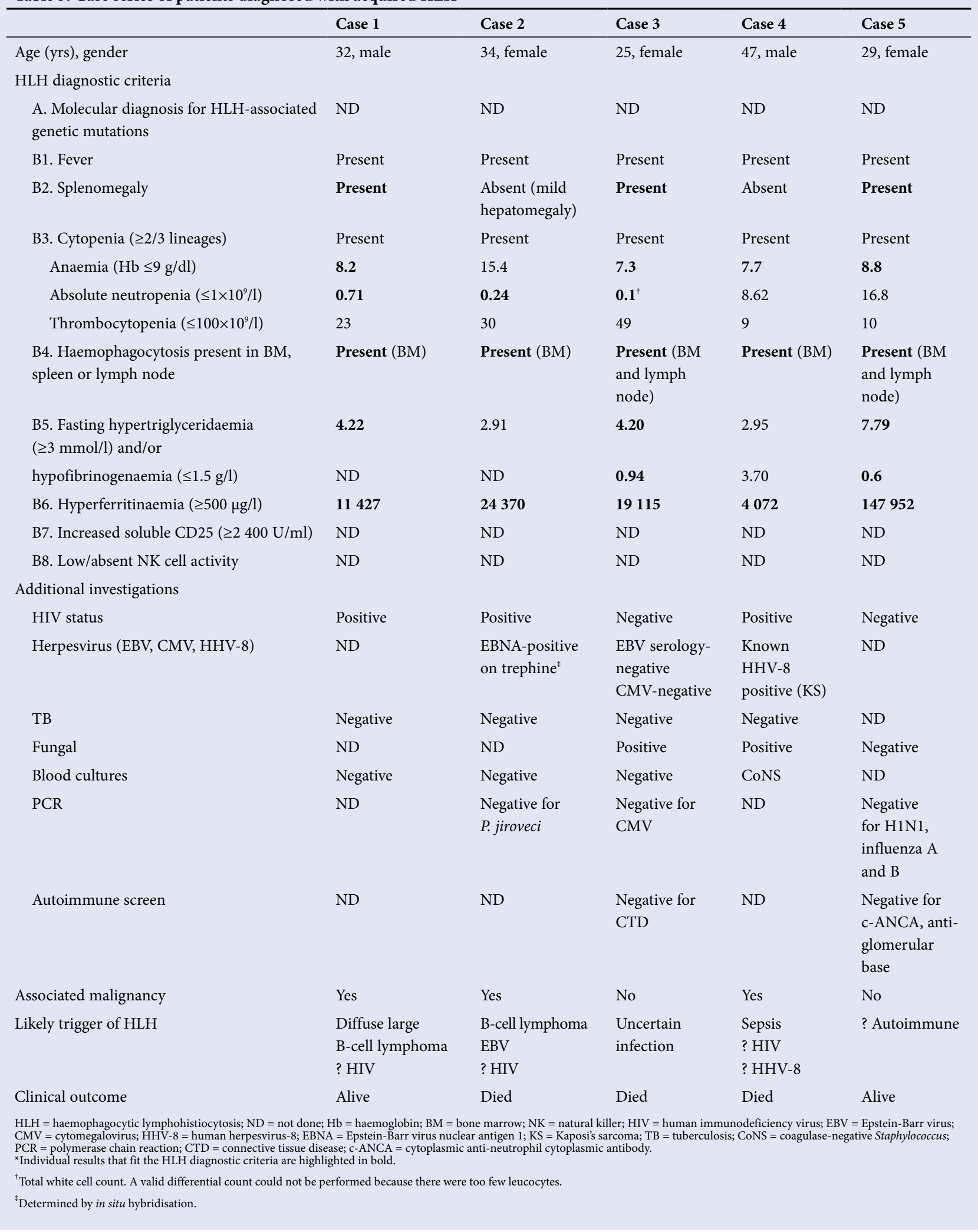

from hepatocytes in the presence of liver infiltration. ${ }^{[13]}$ Ferritin levels were markedly raised in all cases. Though the diagnostic threshold is $500 \mu \mathrm{g} / \mathrm{l}$, reports show that levels $>3000 \mu \mathrm{g} / \mathrm{l}$ should raise strong suspicion and initiate prompt investigation for HLH. Levels $>10000 \mu \mathrm{g} / \mathrm{l}$ have been shown to be $>90 \%$ specific for $\mathrm{HLH}{ }^{[1]}$ though they may also be associated with fulminant hepatic failure. Ferritin is a useful, rapid and relatively cost-effective parameter to measure, especially in resource-limited settings. ${ }^{[18]}$ The rate of ferritin decline following treatment has been shown to be an important prognostic factor for mortality in children. ${ }^{[19]}$ Hypofibrinogenaemia 
(in the absence of liver failure or laboratory features of DIC) suggests immune dysregulation and should arouse suspicion of HLH, especially if associated with splenomegaly. Importantly, the presence of DIC does not preclude HLH as it is common in these patients. ${ }^{[15]}$ Fibrinogen levels were measured in cases 3 - 5 only (as part of DIC screening) with cases 3 and 5 showing diagnostically low levels.

Neither NK cell activity nor CD25 assays were performed, as neither assay is widely available locally. Owing to technical aspects of the assays, if available, and delay in obtaining results, it is recommended that blood be taken at the earliest possible opportunity during work-up for suspected HLH. For all the patients in this series, NK cell or CD25 assays may have been of limited use owing to the advanced stage of disease at time of BMAT. NK cell and CD25 assays may, however, assist in raising the diagnostic pickup rate of $\mathrm{HLH}$, especially if patients do not meet the criteria for the remaining parameters.

Additional investigations were performed on all patients in the search for a trigger for suspected sepsis/SIRS before the diagnosis of HLH was made. These investigations varied between treating physicians and were probably focused according to individual clinical symptoms and comorbidities. The search for infective triggers involved testing for herpesviruses, tuberculosis (TB), aerobic micro-organisms and fungi. Members of the herpesvirus family coincidentally are the most frequent triggers of viral-associated HLH. ${ }^{[5,6,20]}$ These include Epstein-Barr virus (EBV), the reactivation of which has been implicated the most in viral-associated $\mathrm{HLH},{ }^{[2]]} \mathrm{CMV}$ and human herpesvirus 8 (HHV-8). EBV was detected by in situ hybridisation of the trephine in case 2. EBV serology was negative in case 3.

TB investigations were carried out on peripheral blood (case 1), ascitic fluid (adenosine deaminase measurement only, case 4), sputum (cases 2 and 3), urine (case 2), bone marrow aspirate (cases 1 and 4). All yielded negative results. Cases 3 and 4 yielded positive fungal results on peripheral blood cultures. Case 3 had a severe neutropenia of $0.04 \times 10^{\circ} / 1$ at the time of fungal culture sampling, while case 4 had normal absolute neutrophil and lymphocyte counts of $5.19 \times 10^{9} / 1$ and $3.07 \times 10^{9} / 1$, respectively. It is therefore likely that the fungaemia identified in case 3 resulted from HLH-related severe neutropenia and was considered unlikely as an initial trigger. Blood cultures from case 4 yielded a coagulase-negative staphylococcal infection while negative cultures were obtained from the other cases. Cultures of catheter tips, urine and skin swabs were all negative.

PCR assays for potential HLH triggers, Pneumocystis jiroveci, CMV and influenza were performed on cases 2, 3 and 5, respectively and were all negative. CMV is an infrequent trigger of HLH, but has been shown to respond well to intravenous immunoglobulin thereby avoiding the need for chemotherapy. ${ }^{[2]]}$

A connective tissue disease screen was performed on case 3 , as she presented with a history of erythema nodosum that responded well to steroids. Biopsy of the lesion revealed septal panniculitis. She subsequently deteriorated clinically upon withdrawal of steroid therapy. Results of the connective tissue disease screen were negative. Cytoplasmic anti-neutrophil cytoplasmic antibody and glomerular membrane base antibody screens were performed on case 5 as she presented with features of vasculitis and malar rash at time of admission. The results were also negative.

Three of the five cases had a malignancy at the time of diagnosis. In malignancy-associated HLH, HLH can precede the malignancy diagnosis, occur after diagnosis or manifest during chemotherapy. It is largely associated with T-/NK cell lymphomas or leukaemias. ${ }^{[2,5]}$ However, an association with large B-cell lymphomas has been described. ${ }^{[22]}$ It has been postulated that HLH is triggered by release of IFN- $\gamma$ and CD25 from neoplastic cells, causing significant macrophage activation. ${ }^{[5]}$
HIV has been listed as a trigger of HLH in the literature, but the exact mechanism/s by which this occurs is not yet understood. ${ }^{[9,23]}$ HLH is common during the period of seroconversion, though it may occur at any time..$^{[9]}$ There is a paucity of information regarding optimal treatment of HIV-positive patients presenting with HLH. A French retrospective study of $58 \mathrm{HIV}$-positive patients showed that reactive haemophagocytic syndrome was diagnosed in patients with a median $\mathrm{CD} 4^{+}$count of 91 cells $/ \mu$ l, with $35 \%$ of patients having viral loads (VLs) of $<50$ copies $/ \mathrm{ml}$ at diagnosis. ${ }^{[23]}$ Single case reports from Japan reported cures with antiretroviral therapy alone. ${ }^{[9,10]}$ Case 3 had a CD $4^{+}$count of 50 cells $/ \mu$ with a VL of 459444 copies $/ \mathrm{ml}$. Case 4 had $\mathrm{CD}^{+}$count of 586 cells/ $\mu \mathrm{l}$ with a VL of $<20$ copies $/ \mathrm{ml}$, but he had previously been treated for KS, according to clinical information provided. HHV-8 has been shown to act as an HLH trigger in HIVpositive cases in a limited case series. However, the median $\mathrm{CD} 4^{+}$ counts of the patients was significantly lower $(200$ cells $/ \mu \mathrm{l}) \cdot{ }^{[20]}$ Case 1 was HIV-negative on ELISA and p24 antigen-negative at admission. Recent repeat HIV testing revealed that he is HIV-positive with a $\mathrm{CD} 4{ }^{+}$count of 371 cells $/ \mu \mathrm{l}$ and a VL of 104 copies $/ \mathrm{ml}$. Hence, HLH may have been triggered by either seroconversion or malignancy.

The treating physicians were contacted immediately after the diagnosis of HLH was made and were advised to urgently seek treatment advice from a clinical haematologist. Unfortunately, all patients were at advanced stages of disease at the time of BMAT and cases 2 - 4 succumbed to their illness shortly thereafter. Cases 1 and 5 received appropriate treatment after diagnosis and were alive at time of writing.

The normal immune response to antigenic stimuli (viz. viruses, bacteria or malignancies) involves the clonal expansion of specific CD4- and CD8-positive T-lymphocytes along with the generation of cytokines to recruit macrophages to the site of concern. A defect in CTL and NK cell-directed apoptosis (via perforin and granzyme) of these activated clonal lymphocytes once the stimulus has been removed forms the common pathway of familial and acquired HLH. Defective apoptosis results in increasing production of proinflammatory cytokines, resulting in a catastrophic cascade of events, terminating in multiorgan failure and death. HLH is considered to be rare, and much of what is known in the literature is found in paediatric journals concerned with the familial form. As such, acquired HLH remains a largely unknown entity in adult medicine and its diagnosis is frequently missed in ICU settings.

This limited case series suggests that adult acquired HLH may be a common pathology in acute care settings, where it may masquerade as sepsis or SIRS. Unless it is diagnosed early and appropriate treatment is instituted, the mortality rate is high. Much of the information regarding chemo-/immunotherapy has been gleaned from the HLH94 protocol where children under 16 years of age were administered etoposide, dexamethasone and cyclosporine (while awaiting a stem cell transplant if diagnosed with familial HLH or relapsing/nonresponding secondary HLH). A 5-year survival rate of 54\% (standard deviation \pm 6 ) was achieved with the HLH-94 trial - a remarkable improvement when previously the mortality rate approached $100 \%{ }^{[8]}$ Given the complex nature of the condition, treatment requires the expertise of a clinical haematologist or medical oncologist well versed in the complexity and challenges of HLH if cure is to be achieved. The concept of using chemotherapy to treat a non-neoplastic condition may seem drastic to medical personnel not familiar with the disease, but its use is essential to induce apoptosis in the defective NK cells and CTLs and quell the cytokine storm.

Establishing a diagnosis of HLH may be difficult in the early stages of disease, as most diagnostic parameters (apart from the gene-specific assays) are in themselves fairly nonspecific. In the 
case of oncology patients or those with HIV, the list of differential pathologies is considerable. Only when seen together does a picture of immune hyperstimulation and resulting multiorgan failure emerge.

Possible methods to increase the diagnostic pick-up rate of acquired HLH include auto-flagging of haematological results that exceed upper limits for certain diagnostic criteria (e.g. raised ferritin in the presence of low fibrinogen levels). Alternatively, a standard algorithm for work-up of cases of suspected sepsis with unresolving pyrexia and organomegaly could be instituted in acute care settings. Though not part of the HLH diagnostic criteria, the absence of liver dysfunction in a suspected HLH patient should prompt treating physicians to consider alternative diagnoses.

It is important to note that in this case series, patients received a diagnosis of HLH only after BMATs were performed to further investigate cytopenias or possible septic foci. It is not known how many HLH cases may have gone undiagnosed in patients who revealed no haemophagocytosis on aspirates/trephines. Reports on the role of flow cytometry in diagnosing HLH on bone marrow aspirates show promise and may assist in increasing the pick-up rate. ${ }^{[1,24]}$ It is hoped that this case series raises awareness of adult acquired HLH in intensivists, oncologists, physicians and infectious disease experts.

1. Lehmberg K, Ehl S. Diagnostic evaluation of patients with suspected haemophagocytic lymphohistiocytosis Br J Haematol 2012;160(3):275-287. [http://dx.doi.org/10.1111/bjh.12138]

2. Usmani GN, Woda BA, Newburger PE. Advances in understanding the pathogenesis of HLH. Br $J$ Haematol 2013;161(5):609-622. [http://dx.doi.org/10.1111/bjh.12293]

3. Janka G, zur Stadt U. Familial and acquired haemophagocytic lymphohistiocytosis. ASH Education Book 2005;2005(1):82-88. [http://dx.doi.org/10.1182/asheducation-2005.1.82]

4. Jordan MB, Allen CE, Weitzman S, Filipovich AH, McClain KL. How I treat hemophagocytic lymphohistiocytosis. Blood 2011;118(15):4041-4052. [http://dx.doi.org/10.1182/blood-2011-03-278127]

5. Canna SW, Behrens EM. Making sense of the cytokine storm: A conceptual framework for understanding diagnosing and treating hemophagocytic syndromes. Pediatr Clin North Am 2012;59(2):329-344. [http:// dx.doi.org/10.1016/j.pcl.2012.03.002

6. Arceci RJ. When T cells and macrophages do not talk: The hemophagocytic syndromes. Curr Opin Hematol 2008;15(4):359-367. [http://dx.doi.org/10.1097/MOH.0b013e3282f97f88]

7. Machaczka M. Hemophagocytic lymphohistiocytosis in adults. Ups J Med Sci 2013;118(3):201-203. [http:// dx.doi.org/10.3109/03009734.2013.795634]
8. Trottestam H, Horne A, Aricó M, et al. Chemoimmunotherapy for hemophagocytic lymphohistiocytosis: Long term results of the HLH-94 treatment protocol. Blood 2011;118(17):4577-4584. [http://dx.doi. g/10.1182/blood-2011-06-356261]

9. Adachi E, Koibuchi T, Imai K, et al. Hemophagocytic syndrome in an acute human immunodeficiency virus infection. Intern Med 2013;52(5):629-632. [http://dx.doi.org/10.2169/internalmedicine.52.7544]

10. Gotoh M, Matsua J, Gohchi K, Sanaka T, Kawasugi K. Successful recovery from human immunodeficiency virus (HIV)-associated haemophagocytic syndrome treated in highly active anti-retroviral therapy in a patient with HIV infection. Br J Haematol 2001;112(4):1090. [http://dx.doi.org/10.1046/j.1365-2141.2001.02622-7.x]

1. Hot A, Madoux MH, Viard JP, Coppéré B, Ninet J. Successful treatment of cytomegalovirus-associated hemophagocytic syndrome

12. Machaczka M, Vaktnäs J, Klimkowska M, Hägglund H. Malignancy-associated hemophagocytic lymphohistiocytosis in adults: A retrospective population-based analysis from a single center. Leuk Lymphoma 2011;52(4):613-619. [http://dx.doi.org/10.3109/10428194.2010.551153]

13. Okabe T, Shah G, Mendoza V, et al. What intensivists need to know about hemophagocytic syndrome: An underrecognized cause of death in adult intensive care units. J Intensive Care Med 2012;27(1):58-64. [http:// dx.doi.org/10.1177/0885066610393462

14. Rajagopala S, Singh N, Agarwal R, Gupta D, Das R. Severe hemophagocytic lymphohistiocytosis in adults experience from an intensive care unit from north India. Indian J Crit Care Med 2012;16(4):198-203. [http// dx.doi.org/10.4103/0972-5229.106501

15. Raschke RA, Garcia-Orr R. Hemophagocytic lymphohistiocytosis: A potentially underrecognized association with systemic inflammatory response syndrome, severe sepsis, and septic shock in Adults. Chest 2011;140(4):933-938. [http://dx.doi.org/10.1378/chest.11-0619]

16. Henter JI, Samuelsson-Horne A, Arico M, et al. Treatment of hemophagocytic lymphohistiocytosis with HLH-94 immunotherapy and bone marrow transplantation. Blood 2002;100(7):2367-2373. [http://dx.doi. org/10.1182/blood-2002-01-0172]

17. Morrell DS, Pepping MA, Scott JP, et al. Cutaneous manifestations of hemophagocytic lymphohistiocytosis. Arch Dermatol 2002;138(9):1208-1212. [http://dx.doi.org/10.1001/archderm.138.9.1208]

18. Switala JR, Hendricks M, Davidson A. Serum ferritin is a cost-effective laboratory marker for hemophagocytic lymphohistiocytosis in the developing world. J Pediatr Hematol Oncol 2012;34(3):e89-e92. [http://dx.doi. org/10.1097/MPH.0b013e31824227b9

19. Lin TF, Ferlic-Stark LL, Allen CE, Kozinetz CA, McClain KL. Rate of decline of ferritin in patients with hemophagocytic lymphohistiocytosis as a prognostic variable for mortality. Pediatr Blood Cancer 2011;56(1):154-155. [http://dx.doi.org/10.1002/pbc.22774]

20. Fardet L, Blum L, Kerob D, et al. Human herpesvirus 8-associated hemophagocytic lymphohistiocytosis in human immunodeficiency virus-infected patients. Clin Infect Dis 2003;37(2):285-291. [http://dx.doi. org $/ 10.1086 / 375224$

21. Mishra B, Varma N, Appannanavar S, et al. Viral markers in patients with hemophagocytosis: A prospective study in a tertiary care hospital. Indian J Pathol Microbiol 2012;55(2):215-217. [http://dx.doi.org/10.4103/03774929.97876]

22. Altaf S, Atreaga GM, Joshi AY, Rodriguez V. Diffuse large B-cell lymphoma in an adolescent female presenting with Epstein-Barr virus-driven hemophagocytic lymphohistiocytosis: A case report. J Med Case Rep 2012;6:141-146. [http://dx.doi.org/10.1186/1752-1947-6-141]

23. Fardet L, Lambotte O, Meynard JL, et al. Reactive haemophagocytic syndrome in 58 HIV-1 infected patients: Clinical features, underlying diseases and prognosis. AIDS 2010;24(9):1299-1306. [http://dx.doi.org/10.1097/ QAD.0b013e328339e55b

24. McCall CM, Mudali S, Arceci RJ, et al. Flow cytometric findings in hemophagocytic lymphohistiocytosis. Am J Clin Pathol 2012;137:786-794. [http://dx.doi.org/10.1309/AJCPP40MEXWYRLPN]

Accepted 9 December 2013 